\title{
Medicamentos, comunicação e cultura
}

\author{
Drugs, communication, and cultu re
}

\footnotetext{
1 Me s trado em Sa ú de da Família, Un iversidade Estácio de Sá, Unesa.

Rua do Riachu elo 27, Lapa, 20230-010, Rio de Janei ro RJ. mnascimento@sky.com.br
}

Abstract Chemical drugs sign ed a revol $u$ tion in public health activities and in medicine practice, reached hegemony in the contemporary therapeutic and, symbolically, went beyond the boundary of a therapeutic instrument. Presently, they are consumed with the purpose of shaping the body or the beh avior to esthetic and conduct rigid patterns settled in the contemporary culture. The analysis of 237 articles from mass circulation newspaper and magazines, concerning some of the more merchandised pharmaceutics industry drugs in Brazil, revealed a distantness tendency betwe en drugs consumption and medical culture. In these articles, the discourse which favors the drugs consumption was characterized for the association of scientific information's with power, beauty, youth and strength symbols, sustainedon and in the same time re-forcing dominants values in culture, as individualism, competition and consumption. Drugs risks were emphasized in $55 \%$ of the artides, in a discou rse accenting individual autonomy and responsibly in the drugs consumption and its risks. The ask to dominant esthetic and conduct patterns plus the increase risks divulgation tends to dislocate drugs from the field of cure and health to the control and risks, signalizing its re-signification in the therapeutic and culture.

Key words Drugs, Therapeutic, Risks, Communication, Culture
Resumo Medicamentos de base química assinalaram uma revolução nas atividades de saúde pública e no exercício da medicina, alcançando lugar hegemônico na terapêutica contemporânea. A análise de 237 reportagens veiculadas nas décadas de 1980 e 1990, em jo rnais e revistas de larga circulação, sob re alguns dos medicamentos mais consumidos no país, demonstrou que, simbolicamente, estão ultrapassando as frontei ras de um recurso terapêutico. São consumidos cada vez mais com o objetivo de moldar o corpo ou o comportamento a padróes estéti cos e de co $n$ duta rigidamente estabel ecidos na cultura. O disc u rso que favo rece o consumo se caracterizou pela associação de informações científicas a símbolos de poder, beleza, juventude e força, sustentados em e ao mesmo tempo reforçando valo res dominantes na cultura atual, tais como o individualismo, a competição acirrada e o consumismo. A abordagem de riscos prevaleceu em 55\% das reportagens analisadas, em discurso acentuando a autonomia e a responsabilização do indivíduo no consumo de medicamentos e seus riscos. O conjunto das reportagens apontou uma tendência ao descolamen to en tre consumo e cultu ra médica, apoiado na automedicação, e ao deslocamento do medicamento do campo de cura e saúde pa ra o de controle e risco, sinalizando sua re-significação na terapêutica e na cultura.

Palavras-ch ave Medicamentos, Terapêutica, Riscos, Comunicação, Cultura 


\section{Saúde em pílulas}

A descoberta do antibiótico, no início do século 20, é um marco inicial no desenvolvimento da farmacologia atual. Nela, a química ocupa um papel central e os medicamentos são concebi dos em laboratórios para ter uma ação direta con tra doenças específicas em populações.

O êxito inconteste obtido com o emprego de medicamentos no tratamen to de doenças infecciosas, que encabeçavam as taxas de mortalidade na população, en contra-se na base da construção da hegem onia farmacológica na tera pê utica con tem porânea (Alm eida, 1996; Sayd, 1998).

Após a II Guerra Mundial, a indústria farmacêutica con h eceu um período de grande expansão. Integrada aos novos mecanismos de produção e mercado que se consolidavam sob a direção dos Estados Unidos, tornou-se um dos segmen tos mais lucrativos da produção industrial contemporânea.

$\mathrm{O}$ incremento do consumo refletiu as sucessivas vitórias de antibióticos cada vez mais poderosos na corrida con tra bacté rias resistentes, a cres cente diversificação nos produtos da indústria, mas também o desenvolvimento econômico e a formação de sistemas de previdência social. Há que se considerar ainda a pressão de fabricantes, cujos interesses passaram a influenciar autoridades de Estado na área da saúde, médicos, usuários e pesquisadores, influenciandoa demanda por medicamentos e, até certo pon to, produzindo-a (Lexchin, 1995; Ba rros, 1995; Chet ley, 1990).

Estu dos sobre os efei tos nocivos da mercadização no campo da saúde e dos medicamentos, e sobre a iatrogenia médica e farm acológica, emergi ram particularmen te a partir de 1970 (Dupuy \& Karsenty, 1974; Illich, 1975; Foucault, 1977; Clavreul, 1978). Com eles se formulou a crítica à medicalização social, como tendência a considerar as dificuldades da vida probl emas médicos ou instância de dominação política e con trole dos cidadãos.

$\mathrm{Na}$ atualidade, o reconhecimento da con tribuição dos laboratórios farm acêuti cos no controle de doenças convive com inúmeros aspectos que colocam em questão a credibilidade no s etor de medicamentos: multiplicação de similares, que não con tribu em para a melhoria dos recursos terapêuti cos disponíveis; propaganda in tensiva e omissa ou enganosa; a presentação científica inadequada de efeitos indesejados e contra-indicações; aumentos abu sivos nos pre- ços; fraudes; proliferação excessiva no número de farmácias; ausência de farmacêutico de plantão nestes estabel ecimentos; comercialização de medicamentos de uso restrito; convencimen to do con su mi dor no balcão da farmácia - a chamada "empurro terapia", entre outros exemplos (Nascimento, 2003).

A estrutu ra quase mon opólica da indústria farmacêutica, com gra n de con cen tração e caráter internacional, tem se constituído um en trave ao cumprimento das leis que regulamentam a propaganda e a comercialização de medicamentos, especialmente em países pobres e em de s envo lvimento.

$\mathrm{O}$ uso indevido de medicamen tos e a proliferação de reações adversas são des dobramentos perversos de s te quadro. A autom edicação e a prescrição indevida assumem índices alarmantes. Seg u n do Bermu dez (2000), cita n doestimativas da OMS, até 75\% das prescrições de antibióticos, por exemplo, são inadequadas, e a penas met ade das pessor que toma este e outros medicamen tos o faz de modo adequado. Limitações na formação médica e na organização da assistência à saúde também con tribu em na con fig u ração de s teperfil.

No Brasil, mesmo haven do subnotificação, os medicamentos ocupam a primei ra posição entre os agen tes que mais causam intoxicações (Bortolet to \& Boch n er, 1999). A ocorrência de reações adversas a medicamentos atinge cerca de $30 \%$ dos pacien tes hospitalizados, sen do que até $21 \%$ dos casos de morte hospitalar podem estar relacion ados a elas (Ol iveira, 1998).

Estudo publicado no Journal of Americam Medical Association (Lazarou et al.,1998) estimou que, no ano de 1994, a incidência de sérias reações adversas a medicamentos atingiu mais de 2 milhões de pacientes hospitalizados nos EUA, resultando em mais de 100 mil mortes. Tais números coloc a ram estas reações en tre a quarta e a quinta maiores causas de morte na qu ele país. No Canadá, estu do publ ic ado em Ann Pharmacother (Einarson, 1993) estimou os números de internações hospitalares decorrentes de reações adversas a medicamentos nos países de envolvi dos em aproximadamente 5\% s obre o total de admissões.

$\mathrm{Na}$ década de 1980, as críticas à terapêutica farmacológica vieram a extrapolar os meios acadêmicos e intelectuais, com denúncias de crescen tes efei tos indesejados, entre outros aspectos. Tais críticas alcançaram setores urbanos da população, assumindo a forma de demanda por outras formas de bens e serviços de 
saúde. Práticas naturistas, medicamentos fitoterápicos, culturas médicas orientais, s obretudo da Índia e da Chi in a, com suas visões de saúde ditas holistas ou integrais, emergiram, então, obtendo sua oficialização, tanto no Brasil qu a n tono ex teri or (Luz, 1996; 2003).

Os medicamentos farmoquímicos, legitimados pela ciência e identificados ao progresso, passarm a conviver com outras modalidades terapêuticas, como a acupuntura, cujas ra ízes se en con tram na China anti ga e tradicional. De maneira similar, o valor das ervas medicinais e da hom eop a tia foi recu perado e atualizado. Esta coexistência ex pressa e altera, ao mesmo tempo, as maneiras de se pensar a saúde e as estratégias sociais para mantê-la, recuperá-la ou mesmo ampliá-la.

\section{Produção discursiva e construção de sentidos}

Reconhecendo a hegemonia da biomedicina e sua terapêutica fundada na química e na farmacologia, que sustentam a ampla medicalização social em curso des de met ade do século 20, este estu do tem como obj eto os medicamentos el a borados pela grande indústria farm acêutica, e tematiza os con tex tos simbólicos, socialmente construídos, em que se dá o seu con sumo.

O termo biomedicina é adotado segundo Camargo Jr. (1993), ao considerar que esta den ominação reflete mais adequadamente a vinculação desta racionalidade (médica) com o conhecimen to produzido por disciplinas científicas do campo da Biologia. A categoria racionalidade médica é utilizada de acordo com a definição operac i onal proposta por Luz (1995).

O obj etivo geral do estudo se localiza na dim ensão simbólica dos significados e dos sen tidos atribuídos aos medicamentos na cultura, e sua justificação como elemen to fundamental da terapêutica. O objetivo específico é o de identificar os principais discursos e sentidos que circulam e impregnam o imaginário coletivo, nos gran des cen tros urbanos, acerca destes produtos.

Para isto, optamos por analisar o discurso s obre medicamentos veiculado através da gra nde imprensa escrita. Consideramos inegável a im portância da imprensa escrita como prática discursiva, não apenas pela circulação de idéias, argumentos, in terpretações e posicionamentos, mas, principalmentepela influência que exerce no co tidiano de gran de faixa da população. Ao ampliar os discursos disponíveis às pessoas, possibilita-lhes tanto a el eição de novos sentidos quanto a desqualificação de outros, e a construção de versões diversas sobre si mesmas e o mundo a sua volta (Medrado, 1999).

Reunimos 237 reportagens, publicadas em jornais e revistas (figura 1), ao longo das décadas de 1980 (34,2\% das reportagens) e 1990 $(65,8 \%)$. Pri orizamos veículos de largo alcance nas camadas urbanas, que tratam de temas variados de interesse geral e dedicam espaços regulares ao tema específico da saúde. As publicações selecionadas para a análise tematizam algumas categorias de medicamen tos da grande indústria farmacêutica, dentre as mais consumidas pela população: os analgésicos, os antiinflamatórios e os antipiréticos (con tra a dor, a inflamação e a febre), os antibióti cos (con tra a infecção), as vitaminas e os suplementos alimentares.

A leitura das reportagens revelou dois bl ocos temáti cos bastante demarcados, um deles enfatizan doos ben efícios dos medicamentos, e o utro destacando os possíveis ris cos envo lvidos no seu consumo. Seguindo esta organização, os resultados da pesquisa apresen tados a seguir trazem os principais argumen tos favoráveis, contrários ou resistentes ao con sumo dos medicamentos.

\section{Figura 1}

Percen tual de reportagens por veículo impresso pesquisado.

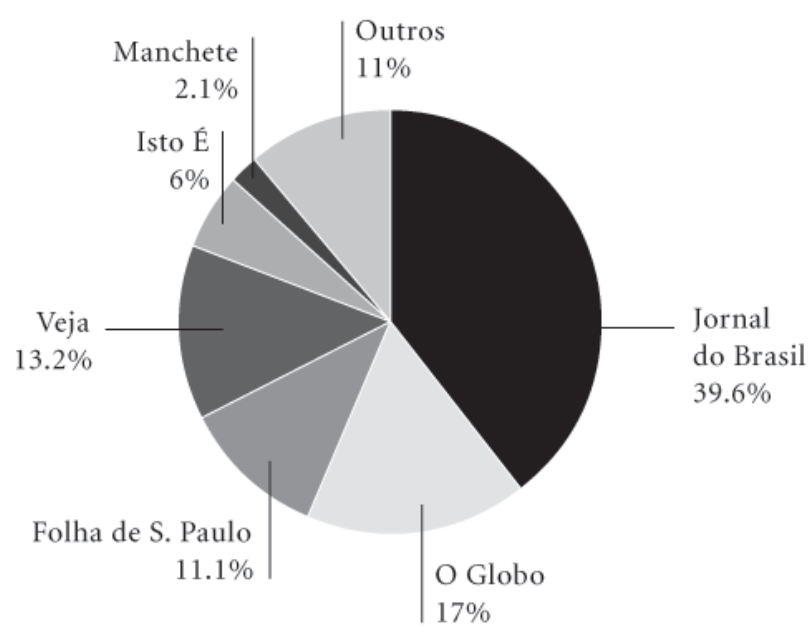


O que buscamos nas reportagens foi principalmente iden tificar as linhas e os contex tos argumen ta tivos em que tais informações en contram-se inseridas. O que nos interessou nesses discursos foi sobretu do seu caráter argumen tativo, que busca a persuasão. Nesta pers pectiva, buscamos identificar a natureza polissêmica das reportagens, que abriga não apenas a regularidade e o consenso, mas a oposição e a contradição. Os diferentes discursos harmonizam ou competem entre si, e criam versões variadas dos mesmos fenômenos sociais.

É importante ressaltar ainda que, embora se trate de uma pesquisa empírica de reportagens da gra n de imprensa escrit a, emb a sada na análise de arti gos e bibli ografia especializados, o estudo também traz uma aproximação ética do tema. Afinal, em nossa socied ade, os medicamentos estão diretamente ligados à preservação da vida, ou à dec retação da morte das pessoas, neste caso por falta deles ou por seu excesso.

\section{Na hora da dor}

Reunimos 82 report gens sobre medicamentos com ações analgésica, antiinflamatória e antipirética. $\mathrm{O}$ ácido acetilsalicílico, a dipirona e o paracetamol foram as substâncias mais mencionadas nas reportagens pesquisadas, seja diretamente e/ou através de seus diferen tes rótulos comerciais. Cada uma destas substâncias compareceu, re s pectivamente, em 56,1\%, 12,2\% e $11 \%$ das reportagens. Por esta razão, tais substâncias terão maior destaque nas observações que se seguem.

A ação analgésica foi a mais mencionada, sen do relacion ada principalmente às dores de cabeça; seguida da ação antiinflamatória, vinculada principalmente às dores musculares, à a rtri te e ao reumatismo, e depois a ação antipirética, associada principalmentea gripes e resfriados.

No conjun to das 82 reportagens pesquisadas (figura 2), 34\% enfatizaram os benefícios do con sumo destes medicamentos, enquanto $55 \%$ deram maior destaque aos possíveis riscos envo lvidos. Apenas 4\% destas reportagens trat a ram o tema atribuin do ênfase similar aos be$\mathrm{n}$ efícios e aos riscos. Sete por cen to delas não se posicionaram a re s pei to.
Figura 2

Analgésicos-antiinflamatórios-antipiréticos. Percen tual de reportagens enfatizandoben efícios e/ou riscos.

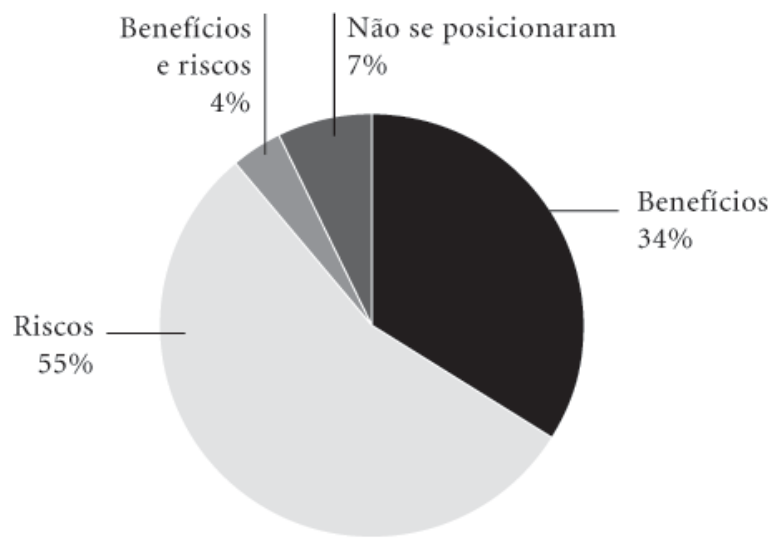

\section{O incen tivo ao con sumo}

O discurso das reportagens que estimula o consumo destes medicamentos tendeu a indicá-los a males diversos considerados de pouca gravid ade, "corriqueiros" ou "passageiros". São males definidos principalmente pela sensação de dor, como sintomabiológico.

Pa ra estes males, po u co definidos, as reportagens não prometeram a cura, mas um alívio rápidodo descon forto. A eficácia destes medicamentos estaria centrada na possibilidade de um bem-estar momentâneo, através da eliminação rápida, mesmo que provisória, de sintomas de males ti dos como banais. Possíveis efeitos adversos não foram mencionados ou o foram de manei ra minimizad a .

O crescimento do co nsumo de remédios mostra que o brasilei ro já se acostumou ao conceito de que as dores de cabeça mais leves não têm cura e que o mal passageiro pode ser contornado com o uso de algum analgésico. "Nada há de mal em tomar um analgésico pa ra uma dor de cabeça eventual", recomenda o médico C. L., do Cen tro Integrado da Dor. "Mas isso não é aconselhável quando a dor se to rna crônica" (Isto É, 6.11.85).

De cada 100 pessoas que por qualquer motivo sen tem dores, num determinado momento, 99 padecem de uma indisposição passageira ou de uma irritação dos nervos provocada por alguma doença possível de ser debelada por meio de me- 
dicação convencional. Pa ra eles, comprimidos de aspirina e remédios eficientes são o que basta (Veja, 20.10.82, p. 76).

Assim como os males a que se destinam, os medicamen tos são igualmen te apre s en t ados de maneira pou co definida, como algo banal, "rotineiro", "rem edinho popular".

A Novalgina faz parte do histórico familiar das pessoas, de tão usada rotineiramente pa ra tudo, define o imunologista F. S. Os outros analgésicos e também os antiinflamatórios pod em ser indicados igualmente pa ra um sem-número de complicações (Jo rnal do Brasil, 4.3.91).

O que é o que é: que os americanos preferem em pas tilhas pa ra chupar, os ingleses no formato efervescen te e os italianos na versão solúvel? É a aspirina (...) o rem edinho mais popular do mundo co mpletou 100 anos (Isto É, 20.8.97, p. 14).

A pouca definição dos medicamen tos e dos males aos quais são indicados, com a promessa de resultados rápidos, foi explorada freqü en temen te através de con cepções mágicas ou miraculosas, como sugerem os títulos de reportagens abaixo relacion ados:

"Velha aspirina é droga mágica para o futuro" (Jo rnal do Brasil, 12.9.88, 1a p.)

"Droga milagrosa" (Jornal do Brasil, 5.12.88, seção Cartas).

"Santo remédio. A força da aspirina" (Isto É Senhor, 8.1.92, p. 37).

\section{O alerta aos riscos}

A ênfase aos ri s cos compareceu em 55\% das reportagens analisadas, relacionados a cada ação (analgésica, antiinflamatória e antipirética) e a c ada substância medicamentosa.

As reportagens inform a ram que o acúmulo de substâncias analgésicas no or ganismo pode a umentar a dor com o passar do tem po. No começo, o analgésico inibe o processo de dor, mas com o uso freqüente aumenta a sensibilidade da pessoa para esta sensação. A dor eventual pode se transformar em crônica: trata-se do efei to inverso ou rebote.

Mais de $80 \%$ das pessoas que sentem dores de cabeça apelam diretamen te pa ra medicamentos analgésicos, antes de tentarem outros métodos paliativos. (...) o uso indiscriminado dos remédios para dores de cabeça pode surtir um efei toinverso. $\mathrm{Ou}$ seja, em vez de curar, acaba intensificando as dores (Jornal do Brasil, 24.12.89, 1o Caderno, p. 14).

O uso de analgésicos por conta própria e em grandes quantidades pode tornar uma dor even- tual na temida dor de cabeça crônica diária. "Mais do que dois co m primidos por semana já são preocupantes...” (Jo rnal do Bra si l,20.4.97, p. 20).

Com relação à ação antipirética, as reportagens analisadas alertaram que o combate à febre baixa a moderada, através de medicamentos, pode contribuir para a evolução da doença, ao invés de con trolá-la ou curá-la. As febre s moderadas ajudam o organismo a mobilizar suas defesas naturais, provocam a formação de anti corpos, colaboram para con ter uma infecção e diminuir do tem po da doença.

Informaram que a decisão de utilizar um antipirético deve levar em consideração, além da temperatura que o termômetro revela, o históri co da pessoa, s eu estado de disposição geral e a presença de outros sintomas. Em situações de febre alta, contínua ou muito freqüente, o melhor mesmo é procurar os cuidados de um médico.

Um estudo com voluntários - que fo ram infectados com vírus da gripe-revel ou que o grupo que comba teu a feb re com aspirina ficou mais vulnerável à doença, assim como a transmitiu mais, do que o grupo tratado com placebo (Jornal do Brasil, 23.1.83).

O primei ro impulso dos pais, quando o filho tem feb re é re co rrer a um antitérmico (...) Alguns pesquisadores acreditam, porém, que dar remédios pa ra ba ixar a febre, especialm en tequando a feb re é fraca, é pior do que esperar que ela desça por si só. Os médicos que pa rticiparam da pe squisa re comendam que os pais devem evitar o recurso ao tylenol, a menos que as crianças estejam com dor e muito desconforto (Jornal do Brasil, 2.10.89).

Com referência à ação antiinflamatória, os riscos foram mencionados segundo substâncias específicas ou grupos de substâncias (antiinflamatórios hormonais e não hormonais). De uma maneira geral, problemas no sistema dige s tivo, como azia, dor, gastrite, úl cera e sangram en to, foram os mais men cion ados.

O ácido acetilsalicílico apres enta ação analgésica e antipirética, além de ser um poten te antiinflamatório. Segundo as reportagens, o uso abu s ivo de ácido acetilsalicílico e as úlcera s decorrentes do con sumo deste medicamen to levam a um número elevado de internações e mortes:

O Governo britânicodecidiu co n trolar a venda de aspirina e pa ra cet a molem toda a Grã-Bretanha. (...) A overd ose de aspirina mata por ano 60 pe ssoas, e cinco mil são internadas com sintomas de intoxicação no mesmo período (O Globo, 28.8.97). 
A aspirina e outros analgésicos semelhantes causam por ano quase tantas mortes quanto a Aids nos Estados Unidos. Segundo estudo publicado hoje na revista americana New England Journal of Medicine, as úlceras provocadas pelo $u$ so exces sivo desses medicamen tos são responsáveis por 16.500 mortes por ano somente nos EUA. O vírus HIV causou 16.685 óbitos no país em 1987 (O Globo, 17.6.99, p. 34).

A dipirona também combina as três ações mencionadas. Em vários países do mu n do a comercialização desta substância é proibida ou restrita, sob a alegação de que seus benefícios não su peram os ris cos associ ados ao seu uso. Está entre as drogas que apresentam os maiores índices de alergia a medicamentos caracterizada por reações de urticária na pele. En tretanto, o efei to mais temido da dipirona, segundo as report a gens analisadas, é a chamada agranulocitose - redução no número de glóbulos bra n cos no sangue - cujo de s dobramen to pode ser fatal.

Ta mbém as dipironas, pro ibidas em diversos países, são aqui vendidas em qualquer farmácia, sob a forma de Novalgina, Commel, Bezerol ou Dorflex, sem que se tomeconhecimento de que se trata de uma droga perigosa, que já causou inúmeros casos de anemia e agranulocitose fatal (Jo rnal do Brasil, 25.9.79).

A maior pesquisa sob re riscos hematológicos da dipirona e outros analgésicos - conhecida como Estudo de Boston - afirma que fato res como subnutrição e atendimento médico inadequado podem tornar mais co muns as conseqüências fatais da agranulocitose, doença (...) provocada pelo uso dos analgésico s (Jo rnal do Brasil, 8.12.90).

O paracetamol, também den om in ado acet aminophen ou acetaminofen o, tem principalmente ação analgésica e antipirética. Segun do as reportagens analisad as, os riscos de intoxicação, relacionados à do s a gem, são os mais freqü en tes en tre seus con sumidores. O uso desta substância de maneira regular e por período de tempo prolongado pode de s en c adear crises renais crônicas e moléstias no fígado. É el evado o número de internações hospitalares e mortes decorrentes do excesso do seu consumo. As crianças e as pessoas que con som em bebida alcoólica são as mais ex postas a estes ri s cos.

Um estudo publicado no Journal of Pediatrics mostra que doses exces sivas de medicamentos contra dor e febre podem trazer sérios prejuizos ao fígado das crianças e até levar à morte. $O$ risco está no acetaminophen, princípio ativo de vários analgésicos e antitérmicos (Revista Manch ete, 21.1.98).
Um grupo de pesquisadores americanos descobriu que o uso regular e prolongado de uma substância conhecida como acetaminofeno, presente em vários analgésicos, aumenta o risco de doenças renais. O acetaminofeno é o principal composto do Tylenol, um dos analgésicos mais popu la res e consumidos no Estados Unidos (Jornal do Brasil, 11.5.89).

\section{O remédio para os antibióticos}

Reunimos 83 reportagens sobre antibióticos. Verificamos que a maioria fez referência aos antibióti cos de uma maneira geral, s em distinguir substâncias ativas ou marcas com erciais.

Oitenta e dois por cen to destas reportagens enfatizaram os ris cos do con sumo de antibióticos, enqua n to apenas $8 \%$ delas destacaram os s eus ben efícios (figura 3). O percentual de reportagens que dedicou ênfase similar a ris cose benefícios foi igual a $2 \%$. O item "outros" na figura se refere a reportagens em que foram mencionadas fraudes, aspectos relacionados à regulamentação ou ao mercado destes medicamentos.

Observamos um grau elevado de consenso nestas report a gens qua n to à percepção do consumo indiscriminado e abusivo de antibióticos e sua relação com a resistência bacteriana e a i n fecção hospitalar.

\section{Figura 3}

Percentual de reportagens enfatizandoben efícios e/ou riscos.

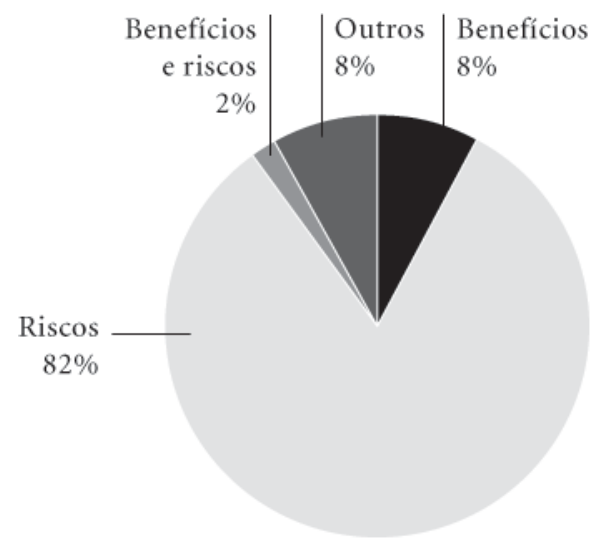




\section{O incen tivo ao consumo}

As reportagens que enfatizaram os benefícios do consumo de antibióticos noticiarm o lançamen to de novos medicamentos ou novas combinações de antibióticos para um fim específico.

O cerco a agen tes ba cterianos está ago ra praticamen te fechado. A ciprofloxacina, uma substância produzida sinteticamente e que ataca por completo o cen tro vital das bactérias causadoras de infecções, é a nova arma dos antibióticos. No Brasil, ela começará a ser comercializada ainda este mês (Isto É Senhor, 12.7.89, p. 59).

Mistu ra de três antibióticos já cura linfomas de estômago (Jo rnal do Brasil, 12.5.94).

Dest acamos a referência à ausência de efeitos colaterais, freqüente nas reportagens que anunciaram novos produtos. Ao lado des te argumento, a menção à expectativa de controle da resistência bacteriana.

Um novo antibiótico capaz de atuar contra inúmeras bactérias, que não provoca efei tos colaterais e que pode diminuir as visitas de pacientes a hospitais acaba de chegar ao Brasil (Jornal do Brasil, 24.4.90. seção Saúde).

A descoberta de dois ti pos de antibióticos (...) revela um contínuo esforço dos cientistas, preocupados em dar um passo à fren te dos micróbios que se to rnam cada vez mais resistentes ao tratamento (Jo rnal do Brasil, 8.8.87).

\section{O alerta aos riscos}

Segundo as reportagens estudadas, en tre os riscos mais comuns, estão aqu eles decorren tes da ação tóxica dos antibióticos no organismo, e estão relacionados às doses de administração do medicamento. As reações tóxicas mais freqüentes consistem em irritação no trato gastrintestinal. Outra classe de riscos são as reações alérgicas, atribuídas à idiossincrasia ou à sensibilização do enfermo ao antibiótico. Os sintomas alérgi cos mais comuns são febre, sensibilidade à luz, rin i tee manifestações atâneas como coceira, verm elhidão da pele e urticária.

Porém, a resistência bacteriana foi o risco mais mencionado, sendo associado ao uso indevido de stes medicamentos.

Abuso de antibióticos no Brasil reforça bactérias (Jo rnal do Brasil, 14.3.87, p. 7).

Uso abusivo de antibiótico cria a su perbactéria (Jo rnal do Brasil 4.10.92, Saúde e Medicina, p. 4).

$\mathrm{O}$ uso indevi do de antibióti cos foi descrito como uso excessivo ou reduzido ou ainda inadequ ado à en fermidade tratada.

O uso excessivo de antibiótico é o principal, porque expõe as bactérias aos medicamentos desnecessariamente, facilitando a seleção natural (Jo rnal da Tarde, 28.9.97).

Muitos pacientes pa ram de tomar a medicação mui to ced o, assim que os sintomas desapa recem. A doença ainda não está curada e o antibiótico só eliminou as bactérias mais "fraquinhas", deixando uma linhagem de bactérias "fortes" se reprodu zi rem (Jo rnal do Tarde, 28.9.97).

A maioria destas infecções respiratórias é provocada por vírus, que não são mortos por antibióticos. (...) Ficamos surpresos ao constatar que um a cada cin co antibióticos éreceitado nesses casos, quando eles nem sequer ajudam (Jornal do Brasil, 18.9.97).

O uso excessivo foi também associado ao em prego de antibióticos na criação de animais para con sumo humano.

O relatório da Organização Mundial de Saúde info rma que (...) mais da metade da produção total de antibióticos é ministrada em animais. Com os bichos, o processo de seleção das cepas éo mesmo do ser humano (Isto É, 5.6.96, p. 40).

A automedicação, facilitada pela chamada empurro terapia praticada nas farmácias, som ada à prescrição médica indevida foram as causas mais mencionadas para explicar o uso indiscriminado de antibióticos.

Apesar de embalados em caixinhas de rótulo vermelho, $80 \%$ dos antibióticos vendidos no país são consumidos por pacien tes que não passaram por um consultório médico. É a automedicação ou a "empu rroterapia"... (Veja, 21.9.94, p. 102).

... mu i tos médicos estão receitando antibióticos de última geração, mais poderosos, para co mbater doenças simples como o resfriado e infecções de pele. Como resultado, os micróbios acabam ficando resistentes e as pessoas mais vulneráveis a infecções (O Globo, 5.2.95, p. 46).

A prescrição indevida, por sua vez, foi vinculada a diversos fatores: à má prática, à qualidade da formação médica, às políticas de saúde, à gran de variedade de antibióti cos existentes no mercado e ainda à pressão exercida por laboratórios farm acêuticos.

Também a infecção hospitalar foi apontada como um ris coimport an te associ ado ao uso de antibióticos.

... o mau uso de antibióticos leva alguns micróbios que nem eram muito importantes ou agressivos a se tornarem temidos agentes de infeç̧ões hospitalares (...) a profilaxia com anti- 
bióticos (quando um pacien te de grande cirurgia toma esse tipo de medicamen to antes, durante e depois da intervenção) é outra prática que, usada em excesso, agrava o problema da resistência ba cteriana (Jo rnal do Brasil, 4.10.92, p. 4).

Ao lado do uso exce s sivo e indevi do de antibióticos, a infecção hospitalar foi associada a o utros fatore s, como a assepsia e a infra-estrutura hospitalar e do setor de saúde, além das condições sociais em que vive a população.

Além do abuso dos antibióticos, há ainda a falta de estrutura e condições de assepsia da maioria dos hospitais - muitos deles não possuem sequer laboratórios, e a desnutrição de grande pa rte dos pacientes (Veja, 23.6.82).

Para finalizar as citações de reportagens nestetema, reproduzimos parte da carta de um leitor expressando sua perplexidade diante do tema.

Li perplexo no noticiário deste jornal que o $u$ so de antibió ti cos por crianças está aumentando vertiginosamente. Se as mães soubessem o mal que estão fazendo a seus filhos estimulando este proced imen to morreriam de vergonha. Na verdade, estão intoxicando as crianças e diminuindolhes aresistên ciaa novas infecções. (...) Na verda- de, o Brasil precisa de um remédio chamado cultura, pa ra dei xar de ser um país colonizado, quintal dos americanos, que aqui desovam suas drogas indiscriminadamente, porque não há lei nem fiscalização (O Globo, 22.1.96, Carta do Lei tor).

Quan toàs explicações en con tradas nas report a gens sobre o uso indevi do de antibióticos, a responsabilização de consumidores (pela autom edicação ou não cumprimen to da prescrição) e de médicos (pela má prescrição e/ou pouca assepsia) compareceu em 42 delas. Precária infra-estrutura hospitalar e políticas de saúde inadequadas foram mencionadas em 24 reportagens, principalmente naquelas em que foi abordado o ris co de infecção hospitalar. A presença de antibióti cos em ração animal comp a receu como explicação em sete reportagens. A atribuição de responsabilidade à indústria e/ou ao merc ado de medicam en tos foi mencio$\mathrm{n}$ ada em duas report a gens (figura 4).

Sublinhamos que a responsabilização de con sumidores e médicos na figura 4 está referida à prática de indivíduos. As reportagens em que esta prática foi associada a políticas públicas foram computadas no item dois (infra-estrutu ra hospitalar e políticas de saúde ).

\section{Figura 4}

Causas atri buídas ao uso indevi do de antibióticos.

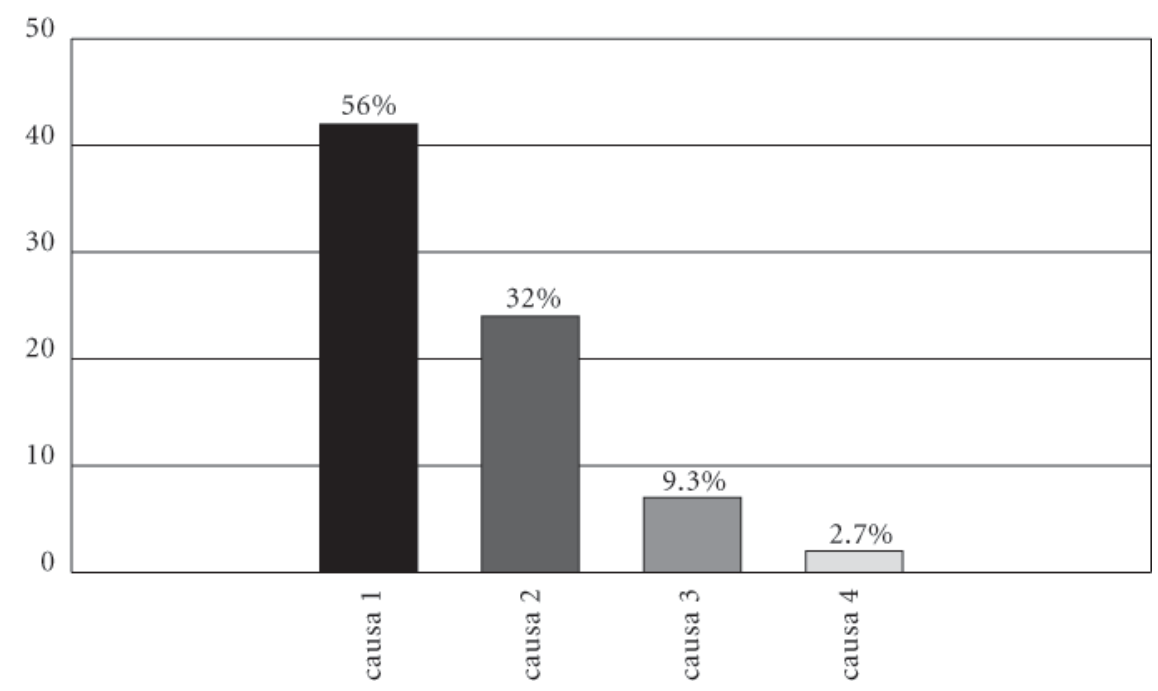

Causa 1 = autom edicação e mápres crição

Causa 2 = infra-estrutura hospitalar e políticas de saúde

Causa 3 = uso de antibiótico em ração animal

Causa 4 = indústria e mercado de medicamentos 
O que queremos destacar é a tendência a focalizar no indivíduo a responsabilização pelos riscos. Seja o indivíduo con sumidor, seja o indivíduo que tem no campo da saúde sua prática profissional.

\section{Vitaminas e suplemen tos alimentares: fon tes portáteis de saúde?}

Reunimos 72 report a gens sobre vitaminas e suplemen tos alimentares. Con si deran do as substâncias tematizadas, verificamos que $72 \%$ destas reportagens destacaram as vitaminas; $17 \%$, os minerais; $5 \%$, vitaminas e minerais, e $6 \%$ enfatizaram outras substâncias (aminoácidos, isotônicos, proteínicos etc.). No total de reportagens pesquisadas, $53 \%$ tro u xeram a palavra vitamina no título.

Trinta e oi to por cen to do conjunto de reportagens enfatizaram os benefícios do con sumo de vitaminas e su plem en tos produ $\mathrm{z}$ i dos pela indústria farmacêutica, enquanto $28 \%$ deram maior destaque aos possíveis ris cos envolvidos. Apenas $8 \%$ delas trataram o tema atribuindo ênfase similar aos ben efícios e aos riscos da utilização destes produtos. O item "outro s" da figura 5 reúne reportagens que não se posicionaram daramen te sobre estes aspectos ou abord a ram outras substâncias.

\section{$\mathrm{O}$ incen tivo ao con sumo}

Os argumentos visando justificar e esti mular o con sumo de complementos alimen $t$ a res indu strializados transitaram en tre alguns temas centrais, envo lven do um ou mais alvos a serem alcançados: correção de deficiência nutricional, prevenção e/ou cura de doenças, ret a rdo do envelhecimento e maior longevidade, aumen to da disposição física e da beleza corporal, compensação de hábi tos de vida pouco saudáveis .

Quando a ênfase do argumen to focalizou a deficiência nutricional, a firmou-se que a escassez de vitaminas não se reduz a limitações no acesso aos alimentos. Desinformação e maus hábi tos também podem provocar a deficiência: o estresse do dia a dia, refeições inadequ adas e apressadas, poluição, consumo de cigarros e bebidas alcoólicas e o uso regular de medicamen tos podem afetar o equilíbrio vitamínico no or ganismo.

Na pesquisa o médico diz que o uso regular de medicamentos pode afetar o equilíbrio vitamínico ... Também o consumo regular de álcool diminui a absorção e utilização de vitaminas ... (O Globo, 17.4.94, reportagem de título "Vit aminas ex i gem cuidado $s$ ") .

Ao lado disto, as reportagens informaram que os alimen tos perdem parte significativa do seu poder nutri tivo com o uso de agrotóxicos,

Figura 5

Vitaminas e suplementos alimentares. Percen tual de reportagens enfatizan doben efícios e/ou riscos.

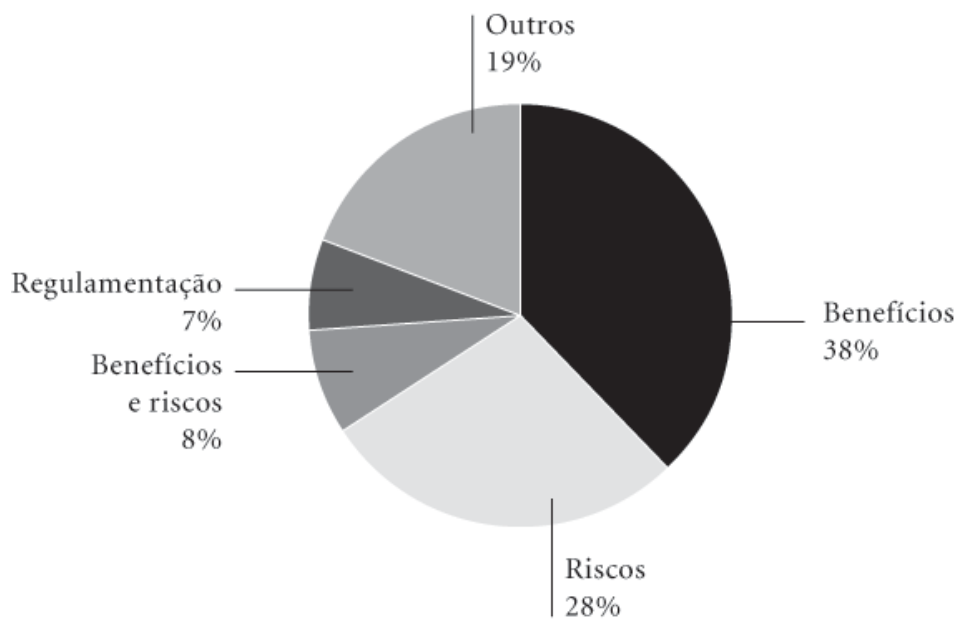


de processos químicos na industrialização, de fervu ra e congel a m en to.

Temos segurança para recomendar a suplementação alimentar com vitaminas ... Não basta ingerir alimentos que contenham essas vitaminas. Eles perdem o poder nu tritivo com a industrialização, a fervura e o congelamento. Ainda estão sujeitos aos agrotóxicos (Isto É, 10.4.96, p. 103).

Foi freqüente a recomendação de complementos alimentares a grupos considerados mais expostos ao probl ema da deficiência: ge stantes e lactantes, crianças, adolescentes, praticantes de esportes, mulheres que tomam pílulas anti concepcionais, pessoas submetidas ao estresse ou a dietas ou ainda ao uso prolongado de medicação, fumantes, con su midores habituais de álcool e idosos. Há alguém que não se en qu ad re nesta classificação?

Quando o argumen to enfatizou a cura e a prevenção de doenças, a vitamina $C$ foi a mais mencionada, recom en d ada principalmentepara ajudar o organismo a combater infecções e a tenuar sintomas de estresse e fadiga. O uso de vitaminas também foi indicado para a prevenção de cardiopatias e outras doenças crônicodegen era tivas.

Vitamina C. É a rainha das vitaminas. Ajuda o organismo a co mbater infecções. Há indícios de que atenua os sintomas do resfriado comum. Pode aumentar a elasticidade dos vasos periféri$\cos$ (Veja, 19.2.86, p. 53).

Megadoses de vitaminas são necessárias? Sim. (...) A implicação dos radicais livres está comprovada não apenas no processo de envel hecimento, mas também nas doenças degenerativas como câncer, a terosclerose e doenças cardiovasculares. Se os radicais livres produ zem doenças pela oxidação, podemos preveni-las por substâncias antioxidantes (Isto É, 10.4.96, p. 103).

Adiar o envelhecimento e alcançar maior longevidade foi outro apelo freqüente nos argumen tos favoráveis ao consumo de complemen tos alimenta res industrializados, realçando-se ben efícios para a memória, a pele e a sexualidade.

De aco rdo com o estudo, um homem que consome diariamente $300 \mathrm{mg}$ de vitamina $C$, na forma natural e em suplementos, pode viver até seis anos a mais do que um individuo que ingere menos de $50 \mathrm{mg}$ por dia (Veja, 20.5.92, p. 53).

A geriatria preven tiva promete a seusclien tes adiar o maior tempo possivel os sintomas atribuídos à senilidade, como a perda da capa cidade de memorização, o endurecimento das articulações e a inapetência sexual (...) aconselha o mé- dicopaulista W. F., um cardiologista que vestiu a camisa de geria tra e re ceita (...) além de vitaminas eenzimas (Veja, 17.7.91, p. 55).

As promessas de juventude e longevidade se apre s en t a ram muitas ve zes de forma integrada, em discurso onde a saúde é associada à juven tu de e à beleza.

A atriz N. P. também não con cebe começar o dia sem a ajuda de vitaminas (...) ela está co nvencida de que pa ra manter a forma e adiar a flacidez nada melhor do que uma cápsula de (...) "Esses suplementos são bons para o corpo, pa ra as unhas e os cabelos", acredita (Veja, 19.2.86, p. 55).

O utro fator de motivação para o con sumo compareceu com freqüência nas reportagens analisadas: o estímulo para se compensar ou pelo menos minimizar possíveis conseqüências indesejadas de práticas e hábi tos de vida reconhecidos na cultu ra como danosos à saúde.

A fumaça de um cigarro, por exemplo, destrói $25 \mathrm{mg}$ de vitamina $C$ e o organismo precisa de uma reserva de $60 \mathrm{mg}$. Não parece lógico que se tome 2 gr por dia? Pode ser, mas melhor mesmo é parar de fumar (Manchete, 29.11.97, p. 60).

Suplem en tos mul tivita mínicossão (...) coquetéis que mistu ram sais minerais e vitaminas (...) Os médicos continuam re ceitando-os para pessoas de vida agitada que não se alimentam direi to, pois podem su prir even tuais carências e não ofere cem riscos de intoxicação (Veja, 28.2.96, p. 76).

O discurso incentivador do consumo defen deu que, para o organismo, não haveria diferença entre as formas de como as vitaminas são produzidas: as sintéticas são idênticas na estrutura química às en contradas nos alimentos. Suas aplicações médicas com obj etivos preven tivos são mu i to importan tes e apenas quantidades exageradas e por períodos muito longos podem provocar efei tos colaterais.

De aco rdo com um trabalho publicado pela Produtos Roche ... os complemen tos vitamínicos em fo rma de drágeas e comprimidos não têm valor calórico. As vitaminas sintéticas são idênticas na estru tu ra química às en co $n$ tradas nos alimentos. Pa ra o organismo não faz diferença como foram produzidas (O Globo, 17.4.94, reportagem de título "Vitaminas exigem cuidados").

Bem aplicados, vitaminas e sais minerais não apresentam praticamen te nenhum efei to colateral (...) O que se sabe ao certo é que não existe nenhum caso de pa ci en te que tenha sido internado por intoxicação de vitaminas. Ninguém tenta se suicidar ingerindo cápsulas de vitaminas (Isto É, maio 98, p. 70, reportagem de título "Vitaminas. Mania Nacional"). 
Este discurso, entretanto, não se utilizou apenas de argumen tos técnicos, apoiados em evidências, teorias ou hipóteses da ciência. Misturou a isto o apelo a símbolos e imagens associados a força, poder, juventude, beleza e sucesso. A menção a personagens famosos, quase sem pre ligados ao esporte ou às artes, foi um recurso permanente na simbolização destes con teúdos.

Garcia, 43 anos, trata nove entre dez artistas da Rede Gl obo que o procuram com freqüencia à base de vitaminas e sais minerais. Boni, Tarcísio, Gória Menezes, Yoná Ma galhães e Tônia Carrero saíram de seu el egan te consultório sobraçando receitas quilométricas (Veja, 19.2.86, p. 56).

\section{O alerta aos riscos}

A abordagem dos riscos e efeitos indesejados destes produtos apareceu principalmente em reportagens veiculadas a partir de 1995. Os títulos e subtítulos destas report gens ilustram a cres cen te preocupação com possíveis danos associados ao con sumo de suplemen tos alimentares.

Estudo contesta eficácia de vitaminas (O Globo, 14.4.94, p. 19).

Minérios milagreiros. Vendidos como novo elixir da longa vida, os minerais podem ser perigosos para a saúde (Veja, 2.11.94, p. 116).

Prateleira suspeita. Novos estudos lançam dúvidas sobre eficácia das vitaminas e outras cápsulas con sumidas por milhões de pessoas (Veja, 31.1.96, p. 74).

Vitaminas em perigo. Novas pesquisas põem em dúvida a eficácia das vitaminas na prevenção de doenças e alertam sobre eventuais riscos à saúde. A milionária indústria dos suplementos alimentares está sob suspeita (Veja, 28.2.96, p. 72).

Overdose de vitaminas. O mercado mundial movimenta bilhões, as pessoas acham que elas são solução para todos os males, mas os médicos alertam: a empol gação com as pílulas coloridas pode acabar em doenças (Manchete, 29.11.97, p. 58).

Vitamina C pode causar câncer (Manchete, 2.5.98).

As reportagens tro uxeram argumentos de profissionais de saúde afirmando que uma alimentação balanceada combin ada a hábi tos de vida saudáveis e exercícios físicos regulares são suficien tes para garantir a obtenção das vitaminas essenciais ao or ganismo e prevenir a deficiência nutricional. Afirmaram que não há evidências científicas suficientes para que se re- comende a ingestão de complementos vitamínicos além dos alimentos, com exceção de quando há deficiência com provada.

Médicos preferem que pacientes obtenham vitaminas em alimen tos e não em produ tos farmacêuticos (Folha de S. Paulo, 3.5.98, Mais, p. 15).

Ambas as insti tuições (Associação Cardiológica Americana e Instituto Nacional do Câncer dos Estados Unidos) recomendam aos médicos que alertem seus pacien tes pa ra o simples fato de que cápsulas de vitaminas não substitu em uma dieta rica em vitaminas (Veja, 31.1.96, p. 75).

$\mathrm{O}$ foco das pesquisas estaria mudando. A ênfase recente da maioria dos pesquisadores estaria se deslocando da descoberta de possíveis benefícios produzidos pelos suplementos alimentares, para o tipo de risco que acarretam. Estes estudos atribu em efei tos oxidantes e até cancerígenos ao con sumo de altas doses de vitaminas.

$O$ caso do betacaroteno, que se transforma em vitamina A no organismo, é intrigante. Sua classificação mudou rapidamen te de um saudável complemen to alimentar para a de uma droga sob séria suspeita. "O mínimo que se pode dizer sobre o betacaroteno é que, por ter sido tratado como alimento, seus benefícios foram superestimados e seus riscos, subestimados ou simplesmente não investigados" diz a pesquisadora B. (Veja, 31.1.96, p. 74).

Um estudo de cientistas americanos e finlandeses mostrou que as vitaminas não previnem o câncer do pulmão. Ao contrário, podem, em alguns casos, aumentar a freqüência desse tipo de tumor e de derrame cerebral. (...) Elas têm um papel importante no metabolismo, mas não devem ser usadas em quantidades adicionais às já existentes nos alimentos (O Globo, 14.4.94, O Mundo/Ciência Viva, p. 19).

... artigo na revista científica $\mathrm{Na}$ tu re de 9 de abril passado, mostrando que a vitamina $C$ provo cou lesão no material genéti co de linfóci tos, células do sistema de defesa do organismo - isto é, as altas doses tiveram efei tos oxida n tes em vez de antioxidantes (Folha de S. Paulo, 3.5.98, Mais, p. 14).

Além da su posta capacidade dos suplementos alimentares em prevenir doenças, também foi questionada sua possível ação con tra o envelhecimento.

Não há qualquer prova conclusiva sobre a capacidade das vitaminas e demais antioxidantes de pa rar o processo de envelhecimen to, como defendem centenas de especialistas no Brasil e no mundo (...) Isso é mais uma dessas ondas que 
acabam se cristalizando à custa da desinformação das pes soas ( $O$ Globo, 10.7.96).

Entre as teorias que destacaram os riscos e prejuízos associados aos suplementos alimentares, afirmou-se que o consumo de minerais pode ameaçar o equilíbrio bioquímico do organismo.

O primeiro senão é o potencial de intoxicação. (...). O segundo perigo é o desequilíbrio que o consumo excessivo de minerais pode provocar. Isso acontece po rque alguns minerais competem pelos mesmos re cepto res no organismo. Assim, se uma pessoa ingerir muito cálcio, pode provocar uma deficiência de magnésio $O$ mesmo acontece com outros pares, como fósforo-ferro, zinco-cobre, sódio-potássio (Veja, 2.11.94, p. 117).

O crescimen to do consumo de complemen tos alimentares industrializados foi associado ao empenho dos fabricantes em vender s eus produtos. Haveria uma insuficiência de critérios científicos fundamentados, combinada a uma agressiva campanha de marketing e publicidade.

Vitaminas e minerais. Uma pitada de ciência, alguma propa ganda e doses maciças na esperança de ven cer o tempo (Veja, 2.11.94, p. 116).

Como resistir ao rei Pelé, o atleta do século, dizendo candidamente no vídeo depois de executar uma "bicicleta" certei ra: "Seja você também um campeão de saúde. Tome Vitasay"? Certamente, o produto (...) não fez de ninguém um campeão a não ser o dono do laboratório (Veja, 19.2.86, p. 56).

As reportagens mencionaram ainda algumas propostas visan do reduzir os riscos, entre elas um maior con trole do governo sobre a indústria.

Cientistas querem que o governo americano impeça a indústria de suplementos a co ntinuar a fazer alegações sem prova (O Globo, 4.2.96).

Os suplemen tos deverão vir a ser tratados como medicação e, portanto, vendidos apenas sob a apresentação de re ceita médica (Diário Catarinense, Revista DC, 19.10.97).

No faturamen to gl obal dos gra n des laboratórios, as vitaminas e os suplem en tos alimen tares estão en tre os produtos mais vendidos, junto dos analgésicos e antibióticos. Há mul tivitaminas indicadas a cada sexo, con cebidas para as crianças (em form a to de pers on a gens infantis), para adultos e paraidosos.

\section{Comunicação e cultura}

No conjun to de report a gens analisadas, observamos o recu rso à ciência como fon te e instância legiti m adora de informações. Os atores de sses discursos foram principalmente especialistas e estudiosos vinculados à prática médica, aos labora tórios farm acêuti cos ou ainda às insti tuições políticas e administra tivas no campo da saúde.

Entretanto, ao lado de informações extraídas de estu dos científicos, en con tramos nas reportagens el em en tos simbólicos, quase sempre volt ados a induzir ao con sumo de medicamentos. Trata-se principalmen te de símbolos de status, poder, sucesso, força, beleza e juven tu de, a través da menção a artistas, atletas e políticos famosos; mas também de símbolos religiosos, em que se vincula o medicamento a uma ação mágica, milagrosa ou santificada.

Caso fo rm assen uma escola de samba seriam imbatíveis na avenida. A comissão de fren te teria como líder ninguém menos que o presidente José Sarney em pessoa. Entre os destaques femininos figurariam atrizes lindas e famosas como Yoná Magalhães, Cláudia Raia e Ni cole Puzzi. O ponta Renato, do Grêmio de Porto Alegre e da Seleção Brasileira, formaria na mesma ala de José Bonifácio de Oliveira Sobrinho, o "Boni", todopoderoso vice-presidente de operações da Rede Globo. A unir este bloco imaginário está uma paixão co mum: o hábi to de complementar as refeições com doses diárias de vitaminas e sais minerais em drágeas (Veja, 19.2.86).

Enten demos que a eficácia deste processo de simbolização se en con tra, em grande medida, em sua adequação a crenças, valores e anseios vivenciados no imaginário coletivo. E se traduz em sua capacidade de intervir na subjetividade coletiva, dando lu gar a procedimentos e modos de vida quase sem pre sustentados no consumo de mercadorias. A articulação dinâmica da autoridade moral da ciência a con textos simbólicos socialmente construídos e partilhados, s ob o caráter maciço e massivo da grande imprensa escrita e da mídia, imprime ao discurso veiculado características particulares. Além de um produto da cultura atual, adquire também a condição de produtor de crenças, valores, desejos e padrões coletivos de procedimentos.

Ao traduzir con cepções específicas de saúde, en fermidade e cura, em articulação a valores fortemente estabelecidos na cultura, o disc u rso veiculado con tri bui ainda para reforçar e 
ampliar tais con cepções e valores. Ilustra isto a ênfase a soluções heteronômicas, instantâneas, de concepção biológica, associadas ao individualismo e ao consumismo.

Vale também ressaltar que, ao combinar ciência, misticismo, símbolos, metáforas e alegorias, parte das reporta gens veiculou publicid ade comercial travestida de jornalismo. Nestes casos, elemen tos da ciência foram utilizados como mais uma estratégia de persuasão, em que a lógica de mercado esteve claramen te s obreposta à lógica da terapêutica e da saúde .

Quanto às motivações para o consumo de medicamentos, destacamos um argumen to freqüen te no discurso analisado: a adequação a valores estéticos e de con duta considerados i deais na sociedade contemporânea. Desta forma, as pessoas são estimuladas a buscar, em fó rmulas farmacológicas, solução para ema grecer ou en gordar, obter massa muscular, driblar sinais de envelhecimento, a umentar a auto-estima ou en con trar mais estímulo para o trabalho, o lazer e o prazer. O que sugere uma tendência ao comando do próprio metabolismo, visando con trolar e moldar o corpo, sentimentos, emoções, desejos e personalidade a formas e obj etivos fortem ente estabel ecidos na cultura a tual (Luz, 2003).

Desta manei ra, além de ser apre sen tado como uma resposta imediata a condições que requerem ações individuais e sociais de fundo p a rasua re s o lução (Fefer, 1999), o medicamento é valorizado como instrumen to de adequação a padrões cultu rais impositivos.

Outro fator de motivação para o con sumo bastante presente nas reportagens foi a promessa de compensar ou, pelo menos minimizar possíveis con s eqüências inde sejadas de práticas e hábi tos de vida recon hecidos na cultura como danosos à saúde. En ten demos que a veiculação desta lógica de compensação, s em o corresponden te alerta sobre os riscos associados ao uso dos medicamentos indicados, repres enta não apenas um contínuo processo de des educação da população, mas também uma agressão à saúde pública.

Noções de prevenção e promoção em saúde, estilo de vida, riscoe res ponsabilização individual pela saúde estiveram combinadas no discurso em favor do con sumo de medicamentos, como uma forma de cuidado aut ô $\mathrm{n}$ omo do corpo e da saúde. O que dá lu gar a uma radicalização no processo de "medicamentalização" social, como tendência a se considerar as dificuldades da vida probl emas solucionáveis pelo con sumo de medicamentos, a gora sob o signo da auton omia e do cuidado do corpo.

Deve ser ressaltado, neste con texto, o descolamen to en tre con sumo de medicamentos e cultura médica, sustentado na automedicação, com respon sabilização do indiví duo pela saúde e seus riscos. Através da divulgação de dados que esti mulam o con sumoaut ôn omo, alerta-se os lei tores-consumidores dos ris cos do medicamen to e das manei ras de evitá-los, responsabilizando-os por efei tos indesejados através do argumen to do uso indevido. A discussão sobre políticas de saúde, mercado de medicamentos ou pressupostos da medicina e da terapêutica medicamentosa ocuparam um espaço reduzido no discurso analisado.

Chamou-nos a atenção ainda a parcialidade do argumen to, como uma caracter í s tica preponderan te do discurso veiculado. Em apenas $5 \%$ das report a gens analisadas observamos peso similar a informações retratando os ben efícios do consumo e os riscos dele decorrentes, limitando-se assim a possibilidade do lei tor se def rontar com os diferen tes aspectos presentes no medicamento.

Finalizando destacamos a predominância na abordagem dos ris cos em 55\% das reportagens analisad as, con tra st a n do com a ênfase aos benefícios do consumo de medicamen tos em $27 \%$ delas. Em 13\% das reportagens, o discurso se referiu a ações de órgãos de fiscalização e con trole, como a Vigilância Sanitária.

A ênfase aos ris cos na imprensa escrita pode ser ex pressão do papel decisio do processo de auton omia e individualização na socied ade pós-industrial, e seu proj eto de socialização de riscos (antes obj eto de peri tos da socied ade industrial), em que o consumidor tende a ampliar sua parcela de responsabilidade com base nas informações a que tem acesso.

Tal fato reforça a questão já men cion ada da parcialidade da informação veiculada. Esperase que os indiví duos domin em situações arri scadas, s em serem capaze s, em razão da com p l exidade envo lvida e dos limites nas informações que lhes são ace s síveis, de tomar as decisões necessárias em uma base fundamen $t$ ada e re s ponsável, ou seja, con si dera n do as possíveis con s eqüências.

De manei ra complexa, o grave probl ema de saúde pública col loc ado pelo con sumo indiscriminado de medicamentos é, ao mesmo tem po, su s ten tado e denu n ciado pela imprensa escrita. Sendo en frentado pela via da autonomia e da responsabilização do indivíduo, mas também 
através de denúncias e escla recimen tos comprom eti dos com uma ética deresponsabilidade com o social.

Por fim, embora sem esgotar as possibilidades de leitura, o dest a que aos ris cos de medicamentos nas páginas da imprensa escrita evoca ainda uma crescente dissonância en tre medicamen tos e saúde no imaginário co l etivo. Constitui o medicamen to como obj eto de de s confiança no poder de cura da medicina hegemônica, em seu projeto terapêutico e em seu aparato tecnológico.

\section{Referências bibliográficas}

Almeida EVA 1996. As razões da terapêutica. Tese de do utorado, Instituto de Medicina Social, Universidade do Estado do Rio de Janeiro.

Barros JAC 1995. Propa ganda de medicamen tos: atentado à saúde? Hucitec-Sobravime, São Paulo.

Barros JAC 2000. A (des)informação sobre medicamentos: o duplo padrão de con duta das em presas farmacêuticas. Cadernos de Saúde Pública16(2):421-427.

Bermudez J 1992. Remédios: saúde ou indústria? A produção de medicamentos no Brasil. Relume-Dumará, Rio de Janeiro.

Bermudez J 1995. Indústria farmacêutica, estado e sociedade. Hucitec-Sobravime, São Paulo.

Bermu dez J 2000. Medicamentos: uma questão polêmica. Revista Ciência Hoje 27(161):60-62.

Bortolet to ME \& Bochner R 1999. Impacto dos medicamentos nas intoxicações humanas no Brasil. Cadernos de São Pública 15(4):859-869.

Bourdieu P 1989. O poder simbólico. Coleção Memória e Sociedade. Ed. Difel-Bertrand Brasil, Rio de Janeiro.

Camargo Jr. KR 1993. Racionalidades médicas: a medicina oci dental con tem porânea. Série Es tudos em Saúde Coletiva no 65. Instituto de Medicina Social, Universidade do Estado do Rio de Janeiro.

Carline EA 1995. Medicamentos, drogas e saúde. HucitecSobravime, São Paulo.

Chetley A 1990. A healthy business? World health and the pharmaceutical industry. Zed Books, London.

$\mathrm{Cl}$ avreul J 1983. A ordem médica. Poder e impotência do discurso médico. Ed. Braziliense, São Paulo (trad. port. de L'Ordre Medical, Paris: Seuil, 1978).

Du p uy JP \& Karsenty S 1979. A invasãofarmacêutica. Ed. Graal, Rio de Ja n ei ro (trad. de L' Invasion Pharm a ceutique, Paris: Seuil, 1974).

Einarson TR 1993. Drug-related hospital admissions. Ann Pharmacother 27(7-8):832-840.

Fefer E 1999. Uso racional de medicamentos, pp. 45-55. In JAZ Bermu dez \& JRA.Bonfim (orgs). Medicament tos e a reforma do setor saúde. Hucitec-Sobravime, São Paulo.
Os significados e sentidos atribuídos aos medicamen tos no imaginário coletivo se relacionam com o discurso teórico oficial, podendo forn ecer-lhe su stentação e eficácia ou motivar a transformação de seus pressupos tos e da prática que lhe é associada.

A indicação de substâncias farmacológicas como instrumento de adequação a padrões dominantes de estética e de con dut a, con ju gada à crescen te divulgação dos riscos decorren tes de seu consumo, ten de a distanciar o medicamento das noções de cura e de saúde, deslocando-o pa ra o campo de intervenção, con trole e ris co.

Foucault M 1977. O nascimento da clínica. Ed. Forense Universitária, Rio de Ja nei ro(trad. Port. deNaissance de la Clinique, Paris: PUF, 1963).

Fu chs FD, Tedoldi C, Ban deira de Mello AA \& Soa res AC 1977. Efei tos inde s ejáveis de fármacos: um estu do da incidência em nosso meio. Revista da Associação Médica do Rio Grande do Sul 21:101.

Giovanni G 1980. A questão dos remédios no Brasil: produção e consumo. Livraria e Editora Polis, São Paulo.

Góes A 2000. Um aliado con tra asbactérias. Revista Ciência Hoje 27(159):57.

Heineck I, Gallina SM, Silva T, Pizzol F \& Schen kel E 1998. Análise da publicidade de medicamentos veiculada em emissoras de rádio do Rio Grande do Sul, Brasil. Cadernos de Saúde Pública 14(1):193-198.

Ill i ch I 1975. A expropriação da saúde. Nêmesis da med icina. Ed. Nova Fronteira, Rio de Janeiro.

Kanji N, Hardon A, Harnmeij er JW, Mamdani M \& Walt G 1992. Drugs policy in developing countries. Zed Books, London.

Lazarou J, Pom eranz BH \& Corey PN 1998. Incidence of adverse drug reactions in hospitalized patients: a meta-analysis of prospective studies. Journal of American Medical Association 279(15):1200-1205.

Lefèvre F 1991. O medicamento como merc a do ria simbólica. Ed. Cortez, São Paulo.

Lexchin J 1995. De ception by design - Pharmaceutical pro$m$ otion in the Third World. Penang: Consumers In ternational Regional Office for Asia and the Pacific.

Luz MT 1995. Racionalidades médicas e terapêuticas alternativas. Cadernos de Sociologia 7:109-128.

Luz MT 1996. A arte de curar e a ciên cia das doenças. Hi stória social da homeopatia no Brasil. Dynamis Editorial, São Paulo.

Luz MT 2003. Novos saberes e práticas em Saúde Coletiva: estudo sobre racionalidades médicas e atividades corporais. Hucitec, São Paulo.

Med rado B 1999. Tex tos em cena: a mídia como prática discursiva, pp. 243-271. In MJ Spink (org.). Práticas discursivas e produção de sentidos no cotidiano: aproxi- 
mações teóricas e metodológicas. Ed. Cortez, São Paulo. Nascimen toMC 1998. De panacéia mística a especialidade médica. A acupuntura na visão da imprensa escrita. História, Gências, Saúde - Manguinhos v(1):99-113.

Nascim en toMC 2003. Medicamen tos: ameaça ou apoio à saúde? Vantagens e perigos do uso de produ tos da indústria farmacêutica mais con sumidos no Brasil: vitaminas, analgésicos, antibióticos e psicotrópicos. Ed. Vieira \& Lent, Rio de Janeiro.

Oliveira GO 1998. A indústria farmacêutica e o controle interna cionaldemedica mentos. Brasília. Gráfica do Senado, Brasília.

Pizzol F, Silva T \& Schenkel EP 1998. Análise da adequação das propa gandas de medicamentos dirigidas à categoria médica distribuídas no Sul do Brasil. Cadernos de Saúde Pública 14(1):85-90.
Rozenfeld S 1989. Uso de medicamentos no Brasil. In JR Laporte \& G Tognoni (orgs.). Epidemiologia do medicamen to. Princípios gerais. Hucitec-Abrasco, São Paulo-Rio de Janeiro.

Rozen feld S \& Pepe VLE 1992. Guia Terapêutico Ambulatorial. Artes Médicas-Abras co, Porto Alegre-Rio de Janeiro.

Sayd JD 1998. Mediar, medicar, remediar: aspectos da terapêutica na med i cina ocidental. Edu erj, Rio de Janeiro.

Sch en kel EP (org.) 1996. Cuidados com os medicamentos. UFRGS-UFSC, Porto Alegre-Florianópolis.

Soa res JCRS 2000. A autonomia do paciente e o processo terapêutico: uma te cedu ra co mplexa. Tese de do utorado. Instituto de Medicina Social, Uerj.

Temporão JG 1986. A propaganda de medicamentos e o mito da saúde. Ed. Graal, Rio de Janeiro.

Artigo apres en tado em 15/03/2005

Aprovado em 25/04/2005

Versão final apres en tada em 25/04/2005 